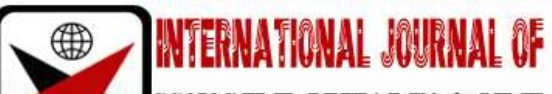

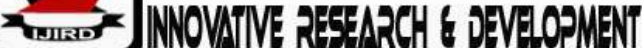

ISSN 2278-0211 (Online)

\section{Effect of Surface Tension of Organic Contaminant on the Movement of Water in Soil}

\author{
Onwugbuta, Godpower Chukwuemeka \\ Lecturer, Department of Biochemistry/ Chemistry Technology, \\ University of Port Harcourt, Nigeria \\ John, Godson Nnamdi \\ Post Graduate Student, Department of Biochemistry/Chemistry Technology, \\ University of Port Harcourt, Nigeria
}

\begin{abstract}
:
This study focuses on the Effect of Surface Tension of Butan-1-ol solutions on the movement of soil water using the drop number and capillary rise methods. In the drop number method, the number of drops of liquid falling from a small orifice is counted for a definite volume, keeping the drop rate constant, while in the capillary rise method, the liquid rises because of its surface tension in a capillary tube of small internal diameter immersed in it. The data by both methods were in excellent agreement. However, the drop number method provided more accurate results as opposed to the capillary rise method. The surface tensions for the capillary rise method were $7.16 \times 10^{-2}, 6.70 \times 10^{-2}, 6.10 \times 10^{-2}$, $5.60 \times 10^{-2}, 4.40 \times 10^{-2}$, and $3.60 \times 10^{-2} \mathrm{~N} / \mathrm{m}$, while that of the drop number method gave $7.12 \times 10^{-2}, 6.70 \times 10^{-2}, 6.00 \times 10^{-2}$, $4.90 \times 10^{-2}, 4.00 \times 10^{-2}$, and $2.90 \times 10^{-2} \mathrm{~N} / \mathrm{m}$, for butan-1-ol in soil water solutions of $0,0.536,0.105,0.211,0.433$, and 0.854 $M$, respectively. It was generally observed that an increase in concentration of butan-1-ol in soil water solutions resulted in a decrease in surface tension. The surface excess concentration in each case was determined from the slope of surface tension graphs using the Gibbs adsorption isotherm; $F=-1 / R T(d y / d \operatorname{lnC})_{T} \mathrm{~mol} \mathrm{~m}^{-2}$. The surface excess concentration for the drop number method was found to be $5.4 \times 10^{-2} \mathrm{~mol} \mathrm{~m}^{-2}$, while the capillary rise method was $4.8 \times 10^{-6} \mathrm{~mol} \mathrm{~m}^{-2}$, respectively. Surface tension is responsible for the shape of water drops and for holding the structures together, as plants may soak up the soil water. The study therefore, reaffirms the fact that substances which lower the surface tension of a solution are adsorbed at the surface and have greater effect on the surface properties hence surface excess of the solute is proportional to the concentration of solute multiplied by the rate of change of surface tension with respect to solute concentration.
\end{abstract}

Keywords: Surface tension, organic contaminant, adsorption, soil water

\section{Introduction}

Some of the gross properties of liquid surface are suggestive of a "skin" that exercises a contracting force or tension parallel to the surface. The molecules at the surface of a liquid are subjected to the strong attractive forces of the interior molecules. A resultant force, whose direction is in a plane tangent to the surface at a particular point, acts to make the liquid surface as small as possible. The magnitude of this force acting perpendicular to the unit length of a line in the surface is called the surface tension, $\mathrm{Y}$ and is expressed in S.I system as $\mathrm{Nm}^{-1}$. The surface or interface where the tension exists is between the liquid and its saturated vapor in air, usually at atmospheric pressure. A tension may also exist at the interface between immiscible liquids commonly called the interfacial tensions (VannOss, 2006). The surface tension of a binary solution is a function of its composition (Hansen and Rodsrun, 1991). Substances which lower the surface tension of a solution are adsorbed at the surface and have, therefore a greater effect on the surface properties than would be predicted under the assumption of uniform distribution throughout the solution.

Surface tension in water describes a condition where the surface of water that is in contact with air acts like a thin elastic sheet. This phenomenon occurs on the surface of liquid when they are in contact with a gaseous medium. When there is contact between the surface of two liquids like water and oil, it is called interface tension. The molecules in the water are drawn together by intermolecular forces known as Vander Waal forces. The molecules on the surface of the water are not surrounded by water molecules on all sides. They will cohese more strongly with neighboring water molecules as opposed to air molecules. This creates a film on the surface which requires a certain amount of force to penetrate (Drelich and Beltran, 2000).

The shape that is formed by drop of water is caused by surface tension. This is because the sphere has the smallest surface area for a given volume. However, the shape of a water droplet is not spherical due to the force of gravity. Whenever you fill a glass of water too far, you may notice afterward that the level of the water is actually higher than the

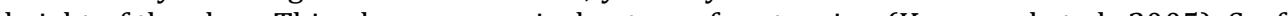


things which are highly dense than water to float, allowing organisms to literally walk on water. An example of such an organism is a spider, which can run across the surface of water due to the intermolecular force of the molecules and the force of the spider which is distributed to its eight legs. Surface tension also allows for the formation of droplets that we see in nature.

Surface tension is of particular interest because of its practical applications. It is an important phenomenon in the study of macromolecular chemistry. It is also an important factor in the concentration of ores by the floatation process (Lam et al., 2002). Surface tension measurements find valuable applications in the biological sciences, particularly in bacteriology. The movement of soil moisture and the passage of sap in plant are only two of many agricultural phenomena that involves surface tension (Bachmann et al., 2000), also relate to such Industrial process as stabilization of foams by preventing contact between the emulsified oil and the dispersed solid. In this study butan-1-ol, a water-soluble organic compound is of special interest because of its properties and uses. Butan-1-ol is a colorless liquid or white, waxy solid. Its resemblance to water diminishes with increasing concentration and therefore, its solubility in waterfalls. Butan-1-ol is used as a solvent especially for lacquers, in artificial flavors as butyl-acetate, and in perfumery. Butan-1-ol could be used to study the biochemistry of living organisms. Its versatility as solvents and raw materials for ethers, acetates, etc. enable it to have a broad end use pattern (Reid and Sherwood, 1958).

Surface tension is a very complicated property of a liquid and it depends upon many variables such as, temperature, composition of the solution, measurement time, materials of the apparatus, and viscosity of the liquid. When a new surface is being formed, surface active chemicals diffuse to the surface and align. During this process, the surface tension changes rapidly and continuously. Pure fluids and solvents have a single surface tension value and are measured with these devices (Drelich and Beltran, 2000). Soil water, sometimes referred to as the soil solution, contains dissolved organic and inorganic substances and transports dissolved nutrients, such as nitrogen, phosphorus, potassium, and calcium, to the plant roots for absorption. Increase in organic matter content of soil water increases surface tension (Tschapek et al., 2006). As surface tension decreases, the ability of the mucilage to wet the surrounding soil particles becomes greater (Henry and Smith, 2002). There are a number of commonly available methods for measuring surface tension of liquid. Each has its advantages and limitations. The choice of a method depends on the nature of system to be studied and its stability, the degree of accuracy required, the condition under which its tension is to be measured and possibly on the ability of the instrument to automate the measurements. Realistically the surface tension value of a liquid will vary depending upon the method used (Hansen and Rodsrun, 1991). The specific objectives of this study are to determine the Effect of Surface Tension of Butan-1-ol in Soil-Water solutions using the Capillary Rise and Drop Number Methods, and to evaluate how increase in concentration affects surface tension.

\section{Materials and Methods}

The Butan-1-ol used was of Analar grade $(250 \mathrm{ml}$ Stock from which different standard solutions were prepared, and soil water was from Abuja campus, University of Port Harcourt, while distilled water was prepared in the laboratory. Five capillary tubes of the same size, 5 beakers of $50.0 \mathrm{ml}$ capacity, clamp stand, travelling microscope, a 100ml graduated cylinder, 5 volumetric flasks of $250.0 \mathrm{ml}$ capacity, mettler top loading balance, 2 burettes (stalagmometers) with good tips, stock concentration of butan-1-ol $(250 \mathrm{ml}), 2.5$ liters of soil water, thermometer, stop watch and a wash bottle were used. All the glassware and capillary tubes were washed with distilled water, rinsed and dried. Different concentrations of butan-1-ol in soil water solutions at $30^{\circ} \mathrm{C}$ were also, prepared using the following parameters. Molecular Formula = $\mathrm{CH}_{3}\left(\mathrm{CH}_{2}\right)_{3} \mathrm{OH}$, Molecular weight $=74.12 \mathrm{~g} / \mathrm{dm}^{3}$, Minimum assay $=95 \% \mathrm{~min}$, Specific gravity $=0.809-0.811 \mathrm{~g} / \mathrm{cm}^{3}$, Average specific gravity $=0.810 \mathrm{~g} / \mathrm{cm}^{3}$.

\subsection{Capillary Rise Method}

The size of the capillary tube was first determined by using the travelling microscope, and the internal diameter was found to be $0.23 \mathrm{~mm}$. It was cleaned with chromic acid solution, rinsed with distilled water and then with the liquid to be used. A $50.0 \mathrm{ml}$ beaker was filled to overflowing with soil water and the end of the capillary tube was pushed well down in the water and held for a few seconds in order to wet the inside of the tube. The tube was withdrawn to a few centimeters while the end was still kept submerged. The tube was clamped to a retort stand. Water rose in the capillary tube and the height, $h$, to which the water had risen in the capillary tube above the level of water in the beaker was measured by means of the travelling microscope. The microscope was then adjusted such that the horizontal cross wire was tangential to the lower meniscus of the liquid inside the capillary tube. The soil water was then tested first. The Main Scale Reading (MSR) and the Vernier Scale Coincidence (VSC) from the vertical scale of the microscope were noted. Then the beaker of water was removed, without disturbing the pointer. The microscope was focused so that the horizontal cross wire was tangential to the tip of the pointer. The MSR and VSC reading were noted. The experiment was replicated three times for each test sample and readings were recorded. The volume of liquid used was noted and the weight was recorded each time the experiment was carried out. The difference between those two observed readings gives the height of the capillary rise ' $h$ '. The radius of the capillary tube was determined and surface tension calculated using the equation: $r=$ $1 / 2 \mathrm{hrpg}$.

Where $\mathrm{r}=$ unknown surface tension $(\mathrm{N} / \mathrm{m}) ; \mathrm{h}=$ height of capillary rise; $p=$ density of butan-1-ol; $\mathrm{r}=$ radius of the capillary tube $\left(0.23 \times 10^{-3} \mathrm{~m}\right)$; and $\mathrm{g}=$ Acceleration due to gravity $\left(9.8 \mathrm{~m} / \mathrm{s}^{2}\right)$.

(b) Drop Number Method

The other burette was clamped and filled with soil water up to about the $8.0 \mathrm{ml}$ line. The burette was opened and water let to drop out at the rate of approximately 60 drops per minute. The timing was read with a stop watch so as to keep the flow rate fairly constant from experiment to experiment. Just when the meniscus passed the $10.0 \mathrm{ml}$ line, the counting of the 
number of drops began. When the meniscus just passed the $20.0 \mathrm{ml}$ line, counting was stopped and the number of drops counted from the $10.0 \mathrm{ml}$ line up to the $20.0 \mathrm{ml}$ line was recorded. The burette was then rinsed and the experiment repeated for three times using the same technique to ensure that the results agreed to within $2 \%$ consistency (Roger and Woodward, 2008). After calibrating the burettes with the water and obtaining reproducible results, the number of drops that was formed upon going from $20.0 \mathrm{ml}$ to $20.0 \mathrm{ml}$ was counted for each of the solutions in turn. Each time the procedure was repeated exactly as when water was used for calibration, three reproducible results were obtained for each concentration hence, the drop rate was kept constant. The experiment was started with the most dilute solution of butan1-ol in soil water and increased progressively. The total number of drops of liquid was weighed and the volume recorded for each trial. Surface tension, $\mathrm{Y}=\mathrm{Y}_{0} \mathrm{n}_{0} \mathrm{~d} / \mathrm{nd}_{0}$.

Where $\mathrm{Y}=$ surface tension $(\mathrm{N} / \mathrm{m})$ of the liquid (Butan-1-ol in soil water solution), $\mathrm{Y}_{0}=$ surface tension of the reference substance (Soil water) given as, $\mathrm{Y}_{0}=7.12 \times 10^{-2} \mathrm{~N} / \mathrm{m}$ at $30^{\circ} \mathrm{C}, \mathrm{d}=$ density $\left(\mathrm{kg} / \mathrm{m}^{3}\right.$ ) of the liquid (Butan-1-ol in soil water solution), $\mathrm{d}_{0}=$ density of the reference substance (Soil water), $\mathrm{n}=$ number of drops of the liquid (Butan-1-ol in soil water solution), and $\mathrm{n}_{0}=$ number of drops of the reference substance (Soil water).

\section{Results and Discussion}

The surface tension of butan-1-ol in soil water solutions calculated from the capillary rise method was compared with those calculated from the drop number method at room temperature $\left(30^{\circ} \mathrm{C}\right)$. The surface tensions for the capillary rise method (Table 1) were $7.16 \times 10^{-2}, 6.70 \times 10^{-2}, 6.10 \times 10^{-2}, 5.60 \times 10^{-2}, 4.40 \times 10^{-2}$, and $3.60 \times 10^{-2} \mathrm{~N} / \mathrm{m}$, while that of the drop number method (Table 2) gave $7.12 \times 10^{-2}, 6.70 \times 10^{-2}, 6.00 \times 10^{-2}, 4.90 \times 10^{-2}, 4.00 \times 10^{-2}$, and 2.90x10-2 N/m, for butan-1-ol in soil water solutions of $0,0.536,0.105,0.211,0.433$, and $0.854 \mathrm{M}$, respectively. The graphs of surface tension versus natural $\log$ of concentration (Figs. 1 \& 2), and the surface tension versus mole fraction of butan-1-ol in soil water solutions (Fig. 3 $\& 4$ ) were also plotted, and the slopes determined in each method used. The surface excess concentration in each case was determined from the slope using the Gibbs adsorption isotherm; $\mathrm{F}=-1 / \mathrm{RT}(\mathrm{dy} / \mathrm{dlnC})_{\mathrm{T}} \mathrm{mol} \mathrm{m}^{-2}$ (Fig. 3 ). The surface excess concentration for the drop number method was found to be $5.4 \times 10^{-2}$, while the capillary rise method was $4.8 \times 10^{-6} \mathrm{~mol} \mathrm{~m}{ }^{-2}$, respectively. From the calculation of surface tensions for various concentrations of butan-1-ol in soil water solutions, it was found that the surface tension decreased with increase in concentration. Also, the density decreased slightly with increase in concentration, and likewise, the mole fraction. It is therefore, pertinent to note that increase in concentration decreases the capillary rise but increases the number of drops falling from a small orifice. From my observation, the separation duration of the two mixed liquids was proportional to that of the deposition of a single drop. The deposition rate of drops is assumed to be dependent on the interfacial drop-liquid medium tension, thus surface tension decreases as the temperature rises and is practically unaffected by changes in total area, pressure, or volume. Increase in temperature increases the vapor pressure hence, decreases the density of the liquid. This fact explains why surface tension varnishes at the critical temperature.

\begin{tabular}{|c|c|c|c|c|c|}
\hline $\begin{array}{c}\text { Butan-1-ol } \\
\text { concentration } \\
\text { (Molality) }\end{array}$ & $\begin{array}{c}\text { InC } \\
\text { (mol dm }^{-3} \text { ) }\end{array}$ & $\begin{array}{c}\text { Mole fraction } \\
\text { (moles) }\end{array}$ & $\begin{array}{c}\text { Density } \\
\mathbf{( K g / \mathbf { m } ^ { 3 } )}\end{array}$ & $\begin{array}{c}\text { Average } \\
\text { capillary rise } \\
\text { (meters) }\end{array}$ & $\begin{array}{c}\text { Surface } \\
\text { Tension (N/m) }\end{array}$ \\
\hline 0 & 0 & 1 & 993 & $6.4 \times 10^{-2}$ & $7.16 \times 10^{-2}$ \\
\hline 0.536 & -2.93 & 0.995 & 992 & $6.0 \times 10^{-2}$ & $6.70 \times 10^{-2}$ \\
\hline 0.105 & -2.25 & 0.990 & 990 & $5.5 \times 10^{-2}$ & $6.10^{-2} \times 10^{-2}$ \\
\hline 0.211 & -1.56 & 0.980 & 985 & $5.0 \times 10^{-2}$ & $5.60 \times 10^{-2}$ \\
\hline 0.433 & -0.84 & 0.960 & 976 & $4.0 \times 10^{-2}$ & $4.40^{-2} 10^{-2}$ \\
\hline 0.854 & -0.16 & 0.924 & 960 & $3.3 \times 10^{-2}$ & $3.60 \times 10^{-2}$ \\
\hline
\end{tabular}

Table 1: Mean Results of Capillary Rise Method

\begin{tabular}{|c|c|c|c|c|c|}
\hline $\begin{array}{c}\text { Butan-1-ol } \\
\text { concentration } \\
\text { (Molality) }\end{array}$ & $\begin{array}{c}\operatorname{InC} \\
\left(\mathrm{mol} \mathrm{dm}^{-3}\right)\end{array}$ & $\begin{array}{l}\text { Mole fraction } \\
\text { (moles) }\end{array}$ & $\begin{array}{l}\text { Density } \\
\left(\mathrm{Kg} / \mathrm{m}^{3}\right)\end{array}$ & $\begin{array}{l}\text { Average number } \\
\text { of drops }\end{array}$ & $\begin{array}{c}\text { Surface } \\
\text { Tension }(\mathrm{N} / \mathrm{m})\end{array}$ \\
\hline 0 & 0 & 1 & 997 & 203 & $7.12 \times 10^{-2}$ \\
\hline 0.536 & -2.93 & 0.995 & 996 & 215 & $6.70 \times 10^{-2}$ \\
\hline 0.105 & -2.25 & 0.990 & 995 & 240 & $6.00 \times 10^{-2}$ \\
\hline 0.211 & -1.56 & 0.980 & 994 & 295 & $4.90 \times 10^{-2}$ \\
\hline 0.433 & -0.84 & 0.960 & 990 & 360 & $4.00 \times 10^{-2}$ \\
\hline 0.854 & -0.16 & 0.924 & 982 & 490 & $2.90 \times 10^{-2}$ \\
\hline
\end{tabular}

Table 2: Mean Results of Drop Count Method 


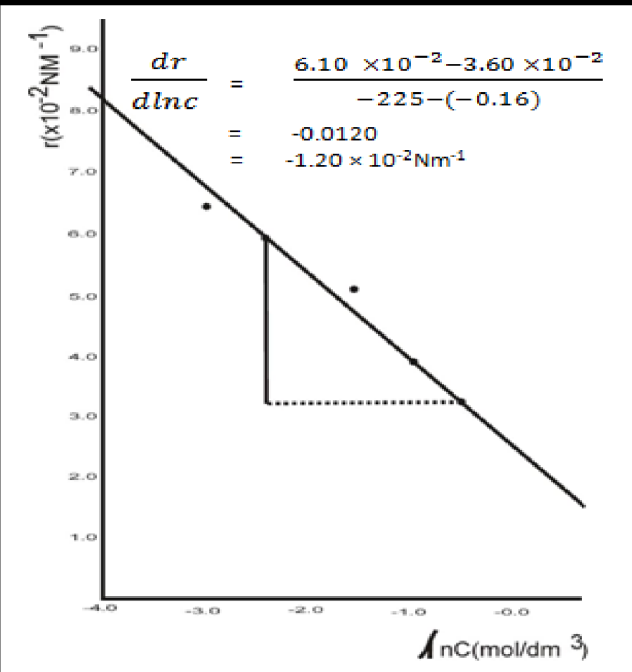

Figure 1: A Plot of Surface Tension versus Concentration of Butan-1-Ol in Soil Water Solutions Using the Capillary Rise Method

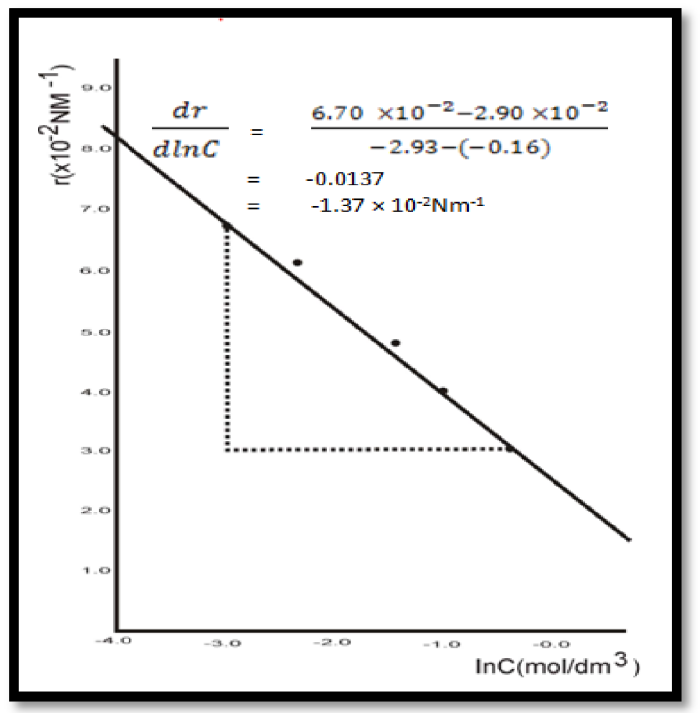

Figure 2: A Plot of Surface Tension versus Concentration of Butan-1-Ol in Soil Water Solutions Using the Drop Count Method

Mole Fraction, $\mathrm{X}=\frac{\text { Number of moles of butanol }}{\text { Total number of moles of solution }}$

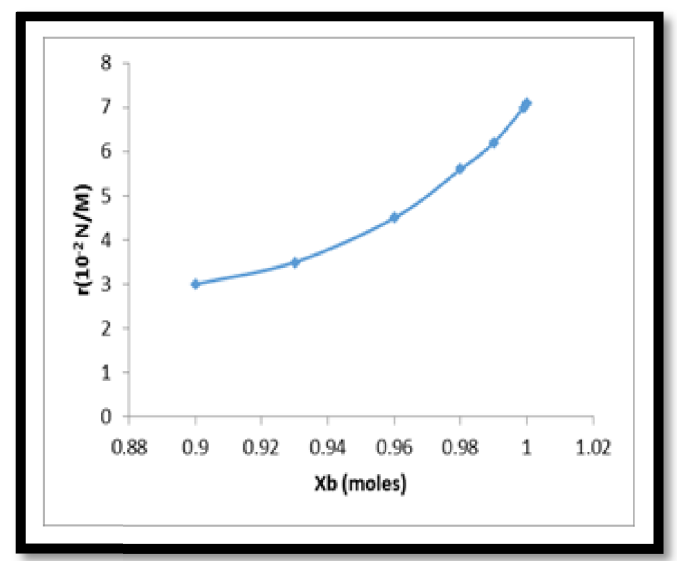

Figure 3: A Plot of Surface Tension versus Mole Fraction of Butan-1-Ol in Soil Water Solutions Using the Capillary Rise Method 


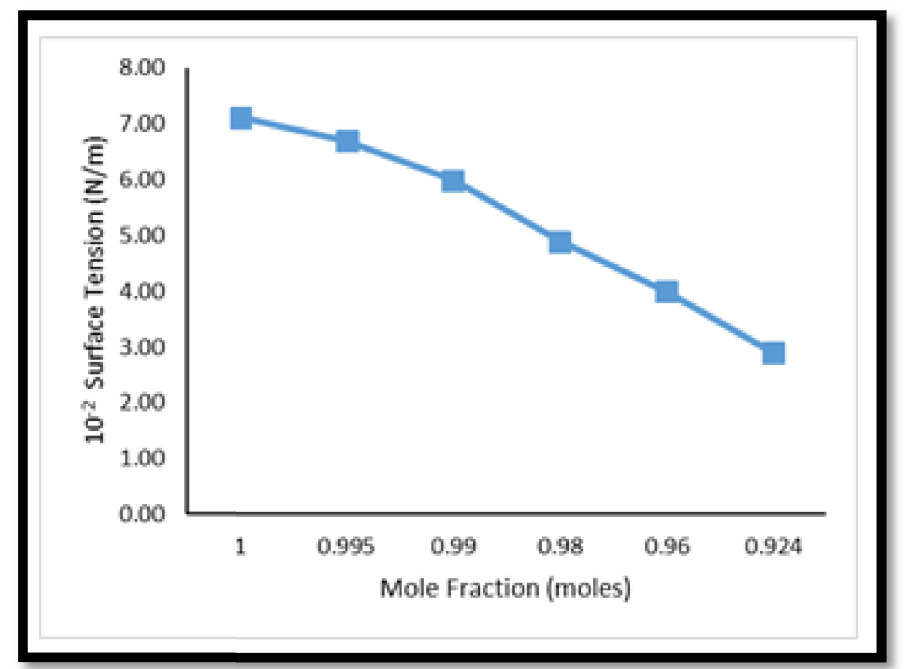

Figure 4: A Plot of Surface Tension versus Mole Fraction of Butan-1-Ol in Soil Water Solutions Using Drop Count Method

\section{Conclusion}

If a solute lowers the surface tension, it concentrates in the outer layers of the solution, but if it increases the surface tension of the solution, it is driven away from the surface. Surface tension then is never increased very much by the addition of a solute, but it may be decreased by a considerable amount. This theory has been checked in the present work using butan-1-ol in soil water solutions as a model. Water molecules form hydrogen bonds with each other to give them a sticky quality, allowing them to form drops. Impurities present in a liquid appreciably affect surface tension. Organic contaminants (butan-1-ol in water solutions) that decrease the surface tension of water have an effect on unsaturated flow through porous media due to the dependence of capillary pressure on surface tension (in agreement with Henry and Smith, 2002). Soil water contains dissolved organic and inorganic substances and transports dissolved nutrients, such as nitrogen, phosphorus potassium, and calcium, to the plant roots for absorption. An increase in the surface tension of a liquid increases the surface flooding and ponding, by saturating the air spaces, thereby blocking the soil pores which in turn, could affect the growth of plants. Adhesion of water to the surface of a material will cause an upward force on the liquid. Capillary action occurs when the adhesion to the surface material is stronger than the cohesive forces between the water molecules. The height to which capillary action will take water is limited by surface tension and gravity.

\section{References}

i. Bachmann, J., Horton, R., Vanderploeg, R.R. \& Woche, S. (2000). The Movement of Soil Moisture and Passage of Sap in Plants. Soil Sci. Soc. Am. J., 64: 564.

ii. Drelich, A.F. \& Beltran, E.G. (2000). Liquid/Liquid System. Interfacial Function. 16: 17-23.

iii. Hansen, F.K. \& Rodsrun, G. (1991). Surface Tension by Pendant Drop: A Fact Standard Instrument using Computer Image Analysis. Colloid and Interface Sciences. 141: 1-12.

iv. Henry, E.J. \& Smith, J.E. (2002). The Effect of Surface-Active Solutes on Water Flow and Contaminant Transport in Variably Saturated Porous Media with Capillary Fringe Effects. Journal of Contaminant Hydrology, 56 (3-4):247270.

v. Karaguzel, C., Can, M.F., Sonmez, E. \& Celik, M.S. (2005). Interface Science. Colloid J, 285: 192.

vi. Lam, C.N.C., Wu, R., Li, D., Hair, M.L. \& Neumann, A.W. (2002). Advanced Colloid. Interface Sci. 96: 169.

vii. Reid, R.C. \& Sherwood, T.K. (1958). The Properties of Gases and Liquids. McGraw-Hill Book Co. New York.

viii. Roger, P. \& Woodward, P.D. (2008). Surface Tension Measurements using the Drop Shape Method. First Ten Augstroms Sci. 186 (1997): 60.

ix. Tschapek, M., Scoppa, C.O. \& Wasowski, C.J. (2006). The Surface Tension of Soil Water. European Journal of Soil Science, 29 (1): 17-21.

x. VannOss, C.J. (2006). Interfacial Forces in Aqueous Media. 2nd ed. CRC Press, New York, 2006. 